\title{
SOMATIZATION AND MEDICALLY UNEXPLAINED SYMPTOMS - PREVAlenCe AND CORRELATES AMONG WOMEN AT NAHAQI - KPK, PAKISTAN
}

1. MBBS, MPH

Assistant Professor

Department of Community Medicine Rehman Medical College, Peshawar.

2. MBBS

Medical Officer

Health Department KPK.

Correspondence Address:

Dr. Ali Raza

Department of Community Medicine Rehman Medical College,

Opposite Rehman Medical Institute Hayatabad Phase V.

doctor.raza@hotmail.com

Article received on:

25/03/2019

Accepted for publication:

25/05/2019

Received after proof reading:

$25 / 06 / 2019$

\section{Ali Raza1, Hajira Zainab²}

ABSTRACT... The study is aimed to determine the prevalence of somatization and its association with anxiety and depression among women at Nahaqi - Charsadda and also to find out the medically unexplained symptoms (MUS) among women at Nahaqi. Study Design: Comparative cross sectional study. Setting: Village Nahaqi at Nahaqi Emergency Satellite Hospital (NESH) Charsadda - KPK, Pakistan. Period: September 2016 to March, 2017. Materials and Methods: 100 females were included in this study after informed consent. American Psychiatric Association, Adult Level 1 Cross-cutting Symptom Measure and Level 2 - Somatic Symptoms Adult Measure containing 23 and 15 questions respectively were used. Data were collected through interviews; entered and analyzed in SPSS. The study was conducted from September 2016 to March 2017. Results: 100 out of 120 women in the age range of 15 to 65 years, mean age $37.09 \pm 12.08$ years responded with response rate of $83.3 \%$. Majority were illiterate (79 $\%)$, married (81 \%) women. $86 \%$ women reported unexplained body aches and pains. The prevalence of anxiety and depression among women at Nahaqi was 50 and $57 \%$ respectively and all items were highly significant $(P<0.000)$ with somatic score categories (Minimal, Low, Medium, High). The prevalence of medically unexplained symptoms was found out to be $84 \%$, which includes all high and medium score cases. 59 women had 5 or more mild to moderate somatic complaints, while 49 reported 5 or more severe complaints. The most frequent complaints were aches and pains (headache, backache and musculo-skeletal aches and pains) followed by lack of energy, general asthenia. Conclusion: Nearly every second women was noted to have unexplained aches and pains, which shows that somatization is a frequent complaint in primary health settings. Majority cases were milder, however, patients showing severe impairment or more complaints they need particular attention. Although MUS result in extra stress on health services utilization in women visiting a rural health facility - Nahaqi; those with serious impairment shall be referred for psychiatric evaluation. A comprehensive medical, psycho-social model that involves community shall be formulated to address this issue.

Key words: $\quad$ Anxiety, Depression, Female Population, Medically Unexplained Symptoms (MUS), OPD, Somatoform Disorder.

Article Citation: Raza A, Zainab H. Prevalence of somatization and correlation with anxiety and depression.Professional Med J 2019; 26(7):1042-1050.

DOI: 10.29309/TPMJ/2019.26.07.3444

\section{INTRODUCTION}

The term medically unexplained symptom (MUS) is popular among physicians and general practitioners to refer to physical illness of their patients when the etiology is not clear. The patient's bodily complaints are not in accordance with the psycho-pathological factors of the patient. $^{1}$

Diagnostic and Statistical Manual for Mental Disorders - IV (DSM - IV) and International Classification of Diseases version 10 (ICD - 10) classify such symptoms that cannot be medically explained in somatic disorders category.

The term "somatization" is frequently used to differentiate medically unexplained somatic symptoms from those which are part of a known organic disease. ${ }^{1}$

According to DSM-IV, somatoform disorders comprise of psychological disorders divided in sub categories, the patient experiences physical complaints that are unclear and cannot 
be fully explained by any underlying general medical or neurologic condition. ${ }^{2}$ However, the various diagnostic subcategories of somatoform disorders have overlapping symptoms and are used less commonly by general physicians. ${ }^{3}$

The somatoform disorders are associated with a great deal of stigma; the patients may be dismissed by their physicians as having problems that are 'all in their head'. It increases use of medical services independent of any accompanying psychiatric or no psychiatric disorder and leads to frustration in both the patient and the clinician. ${ }^{4}$

Medically unexplained symptoms (MUS) account for approximately $50 \%$ of new medical outpatient visits especially in primary care settings. ${ }^{1,5,6}$ Prevalence rates for various sub categories of somatoform disorders varies from $10 \%$ to $25 \%$ in the general population; While MUS prevalence rates show wide heterogeneity with different authors describing different values depending upon the population studied and diagnostic criteria used. MUS defined as at least one physical symptom of mild severity from the last seven days; its prevalence in primary care setting is reported to be between $25 \%$ and $50 \%{ }^{7}$

Ohaeri \& Odejide and Mumford et al have reported the incidence of psychological morbidity to range from $20 \%$ to $80 \%$ in various cultures among the developing countries. Similar patterns were determined by number of other studies. ${ }^{8}$ According to a study, the overall prevalence of somatoform disorders was 10.84 per 1000 population, 15.98 per 1000 among women and 8.01 per 1000 among men. ${ }^{9}$ The disorder usually effects individuals before age of 30 , sometimes in teenage and occurs more often in women than in men. ${ }^{2,10}$ Somatization often occurs in primary care patients. ${ }^{11}$ There is increased incidence of somatization in women with a history of physical,

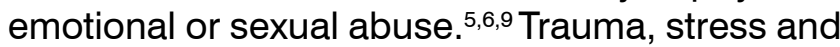
poverty also contribute to it. The most common complaints include headaches, stomach aches, musculoskeletal pains, back pain, dizziness and fatigue. ${ }^{12}$ Multi-system involvement from cardiac manifestations to urogenital symptoms have been seen as somatic complaints.
Patients with somatization typically present to general medical settings rather than to mental health settings. ${ }^{13}$ The unclear physical symptoms lead to general health anxiety; disproportionate disability; negative reactions toward the physician or related health personnel; and, noncompliance with diagnostic or treatment efforts. Such patients place significant burden on the healthcare system, with heavy and repeated utilization of health resources. ${ }^{14}$ Timely diagnosis combined with collaborative and planned psychiatric and medical interventions may decrease significant long-term morbidity. $50 \%$ to $75 \%$ of the patients with MUS improve, whereas $10 \%$ to $30 \%$ of patients with MUS deteriorate. ${ }^{15}$

In Pakistan somatoform disorders possess an obvious diagnostic dilemma. The cornerstone of the management is proper evaluation of the patient involving medical, psychiatric and psychosocial aspects. In non-western cultures like India and Pakistan, the somatization tendency in particular females and patients with depression is more. Most of the time, they present with Medically Unexplained Symptoms manifesting as chronic pain syndromes or as gastrointestinal manifestations. The most reported gastrointestinal symptom was decreased appetite (67.7\%) followed by constipation (57.7\%) and diarrhea $(42.3 \%){ }^{16}$

Research in Pakistan showed that $66 \%$ of women and $25 \%$ men suffered from anxiety and depressive disorders whereby the complaints predominantly were somatic in nature. ${ }^{5}$

The morbidity associated with medically unexplained symptoms can be significant. The physical symptoms are severe enough to affect ones occupation and social relationships. The affected person do frequent consultations and take medications hence a lifelong history of 'sickliness' is often present. Limited researches regarding MUS have been done both internationally and nationally but not in rural areas of KPK, Pakistan therefore, this study aimed to determine the prevalence of somatization and medically unexplained symptoms among women at Nahaqi, KPK-Pakistan. 


\section{OBJECTIVES}

1. To study the association of somatization, with anxiety and depression in women attending Nahaqi Emergency Satellite Hospital.

2. To determine the prevalence of medically unexplained symptoms (MUS) among women at Nahaqi.

3. To compare the symptom profile of patients with somatoform disorders and its association with anxiety and depression.

\section{METHODOLOGY}

\section{Inclusion Criteria}

1. Females in the age range of 15-65 years.

2. Adult females visiting Nahaqi hospital who were willing to participate in the study.

\section{Exclusion Criteria}

1. Those unwilling to participate in the study.

2. Females who were suffering from chronic diseases.

\section{Study Period}

The study was conducted from September 2016 to March, 2017.

\section{Study Setting}

The study was conducted at Nahaqi Emergency Satellite Hospital (NESH), Charsadda, KP, Pakistan; an outreach community program of Rehman Medical College Peshawar since August 2014. This emergency satellite hospital is a rural health center providing comprehensive primary Health care services to a defined community. Outpatient departments (OPD) of seven specialties are active in the health facility.

\section{Study Design}

This was a comparative cross-sectional study. Data was collected by filling structured questionnaires through interviews. Information regarding psycho somatic symptoms, and related factors were surveyed.

\section{Study Population}

The study participants comprised of females presenting to OPD's at Nahaqi emergency satellite hospital Charsadda.

\section{Survey Tool}

A valid tool DSM-5 Level 1 Self-Rated CrossCutting Symptom Measure-Adult containing 23 questions and Level 2-Somatic Symptoms - Adult Patient (adapted from Patient Health Questionnaire (PHQ-15)) containing 15 questions were administered to study participants after informed consent. Out of 120 females 100 agreed to participate in the study.

The level 1 self-rated cross cutting symptom questionnaire assess 13 psychiatric domains, including depression, anger, mania, anxiety, somatic symptom, suicidal ideation, psychosis, sleep problems, memory, repetitive thoughts and behaviors, dissociation, personality functioning and substance use. Each item inquires about how much the individual has been bothered by the specific symptom during the past 2 weeks. The measure is validated and has got a good test retest reliability. ${ }^{17}$

Those completing DSM Level 1 cross cutting questionnaire, were given level 2 somatic symptom adult measure. The patients were asked to complete questionnaire based on their past 1 week's feelings/complaints that have been bothering them. ${ }^{18}$

\section{Analysis Plan}

\section{Level 1 Cross Cutting Measure}

Each item on Level 1 Cross Cutting Measure is rated on a 5 -point scale $(0=$ None, $1=$ Slight or less than a day or two, 2 = Mild or several days, $3=$ Moderate or More than half the days, and $4=$ severe or nearly every day). The score on each item within a domain should be reviewed, because additional inquiry is based on the highest score on any item within a domain. A rating of mild i.e 2 or greater on any item within a domain warrant additional inquiry.

\section{Level 2 Adult Somatic Measure}

Each item on the $\mathrm{PHQ}-15$ is rated on a 3 point scale $(0=$ Not bothered at all; $1=$ bothered a little; 2 = bothered a lot). The total score range from 0 to 30 , with highest scores indicating greater severity of somatic symptoms. The raw 
scores on the 15 items are summed to obtain a total raw score and interpreted according to Table below.

\section{Interpretation Table for Level 2 Somatic Adult Measure}

\begin{tabular}{|l|c|}
\hline Levels of Somatic Symptom Severity & PHQ- 15 \\
\hline Minimal & $0-4$ \\
\hline Low & $5-9$ \\
\hline Medium & $10-14$ \\
\hline High & $15-30$ \\
\hline
\end{tabular}

Data were entered and analyzed by SPSS 16 . Descriptive statistics and Chi-Square tests were done, taking $P$ value $<0.05$ as significant.

\section{RESULTS}

A total of 120 females patients in out-patient departments of Nahaqi emergency satellite hospital were approached to participate in the study out of which 100 consented. The age of the participant females ranged from 15 to 65 years with mean of $37.09 \pm 12.08$ years.

Regarding marital status, majority (81\%) were married, 11 were unmarried while 08 were widow. Figure-1.

unmarried $\square$ married widow

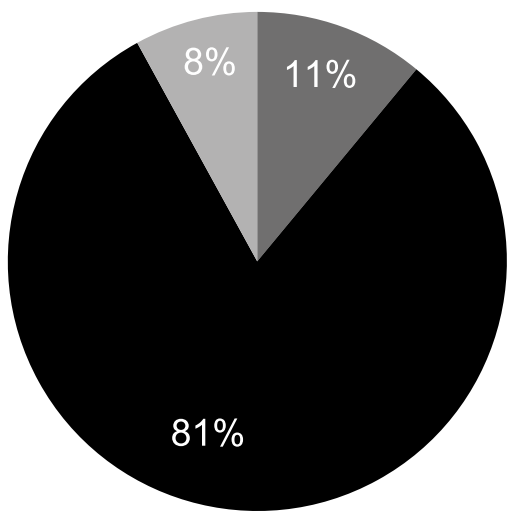

Figure-1. Marital status of participants

Educational status is mentioned in Figure-2. Significant number of female's i.e $79 \%$ were illiterate, while only $04 \%$ had 10 years of education.

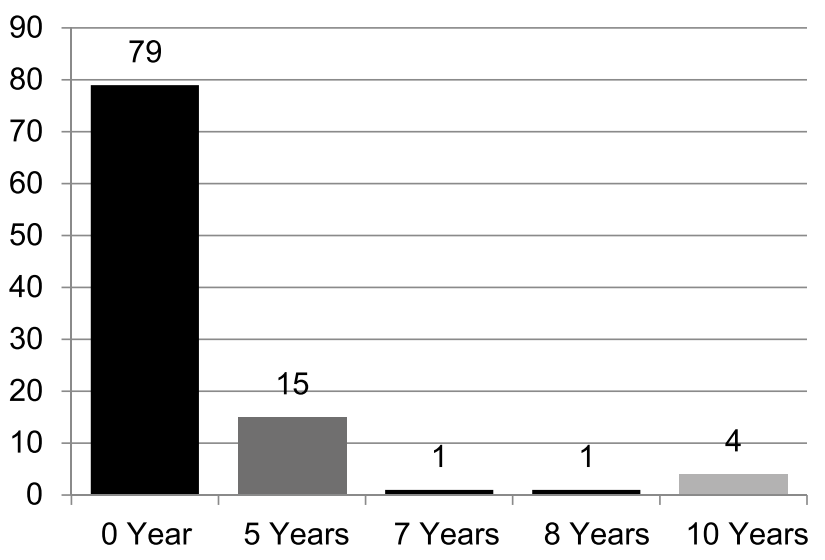

Figure-2. Educational status

\section{Prevalence of Somatization}

The somatization was assessed on Likert scale using two questions (item 9 and 10) from DSM-5 level 1 cross-cutting adult symptom measure;

1. Have you been bothered by unexplained aches and pains?

2. Feeling that your illnesses are not being taken seriously enough?

Minimum score of 2 i.e Mild symptoms were regarded as positive cases needing further inquiry. For question one (item 9); being bothered by unexplained aches and pains $86 \%$ of the cases scored more than 2. For second question (item 10); feeling that your illnesses are not being taken seriously $40 \%$ scored more than 2 i.e reported such feeling in mild to severe degrees.

Table-I shows the respective percentages. The chi-square test between somatic categories (Minimal, Low, Moderate and Severe) and items 9 and 10 from Level 1 questionnaire was found highly significant for unexplained body aches and pains. The percentage for moderate and severe degrees for positive cases was found out to be 39.5 and $51.2 \%$ respectively.

Level of Anxiety and Depression and its Association with Somatic Symptoms

The depression and anxiety were assessed on Likert scale using two and three questions respectively (item 1 and 2 for depression and Items 6 to 8 for Anxiety) from DSM-5 Level 1 adult cross-cutting symptom measure; Items 1 and 2 
screening Depression were:

1. Little interest in doing things in the past 2 weeks?

2. Feeling down, depressed and hopeless?

\begin{tabular}{|c|c|c|c|c|}
\hline $\begin{array}{c}\text { Intensity } \\
\text { and Level } \\
\text { of Somatic } \\
\text { Symptoms }\end{array}$ & $\begin{array}{c}\text { Fre- } \\
\text { quency }\end{array}$ & $\begin{array}{c}\text { Cut off } \\
\text { Value } \\
\text { Assigned }\end{array}$ & $\begin{array}{l}\text { Per- } \\
\text { cent }\end{array}$ & $\begin{array}{c}\text { P- } \\
\text { Value }\end{array}$ \\
\hline \multicolumn{5}{|c|}{ Item 9: Unexplained Pains } \\
\hline None & 05 & \multirow{2}{*}{1} & \multirow{2}{*}{$14 \%$} & \multirow{5}{*}{$\begin{array}{c}\mathrm{P}< \\
0.000\end{array}$} \\
\hline Slight & 09 & & & \\
\hline Mild & 23 & \multirow{3}{*}{2} & \multirow{3}{*}{$86 \%$} & \\
\hline Moderate & 41 & & & \\
\hline Severe & 22 & & & \\
\hline \multicolumn{5}{|c|}{ Item 10: Feeling your illnesses not taken seriously } \\
\hline None & 40 & \multirow{2}{*}{1} & \multirow{2}{*}{$60 \%$} & \multirow{5}{*}{0.031} \\
\hline Slight & 20 & & & \\
\hline Mild & 19 & \multirow{3}{*}{2} & \multirow{3}{*}{$40 \%$} & \\
\hline Moderate & 10 & & & \\
\hline Severe & 11 & & & \\
\hline Table-I. & $\begin{array}{r}\text { Juency a } \\
\text { sym }\end{array}$ & $\begin{array}{l}\text { intensity } \\
\text { oms }\end{array}$ & som & \\
\hline
\end{tabular}

Items 6 to 8 screening Anxiety were:

1. Feeling nervous, anxious or worried?

2. Feeling panic?

3. Avoiding situations that make you panic?

Minimum score of 2 i.e mild symptoms were regarded as positive cases needing further inquiry. In Item 2, $69 \%$ reported being depressed and hopeless. Similarly, Items 6 and 7, $64 \%$ women expressed being anxious or feeling panicked during their day to day affairs. Only 43 $\%$ however, admitted avoiding situations that can elicit panic or anxiety.

Table-Il shows the respective percentages. The chi-square test between somatic categories and depression and anxiety items was highly significant for nearly all items, which means that somatization was related to depression and anxiety.

\begin{tabular}{|c|c|c|c|c|}
\hline $\begin{array}{l}\text { Depression } \\
\text { Levels }\end{array}$ & $\begin{array}{c}\text { Fre- } \\
\text { quency }\end{array}$ & $\begin{array}{l}\text { Cut off } \\
\text { Value } \\
\text { Assigned }\end{array}$ & $\begin{array}{l}\text { Per- } \\
\text { cent }\end{array}$ & $\begin{array}{c}\text { P- } \\
\text { Value }\end{array}$ \\
\hline \multicolumn{5}{|c|}{ Item 1: Little Interest In Doing Things } \\
\hline None & 12 & \multirow[b]{2}{*}{1} & \multirow{2}{*}{$45 \%$} & \multirow{5}{*}{0.007} \\
\hline Slight & 33 & & & \\
\hline Mild & 27 & \multirow{3}{*}{2} & \multirow{3}{*}{$55 \%$} & \\
\hline Moderate & 19 & & & \\
\hline Severe & 09 & & & \\
\hline \multicolumn{5}{|c|}{ Item 2: Feeling Down, Depressed And Hopeless } \\
\hline None & 08 & \multirow{2}{*}{1} & \multirow{2}{*}{$31 \%$} & \multirow{5}{*}{$\begin{array}{l}\mathrm{P}< \\
0.001\end{array}$} \\
\hline Slight & 23 & & & \\
\hline Mild & 29 & \multirow{3}{*}{2} & \multirow{3}{*}{$69 \%$} & \\
\hline Moderate & 29 & & & \\
\hline Severe & 11 & & & \\
\hline \multicolumn{5}{|c|}{ Anxiety Levels } \\
\hline \multicolumn{5}{|c|}{ Item 6: Feeling nervous, anxious or worried } \\
\hline None & 14 & \multirow{2}{*}{1} & \multirow{2}{*}{$36 \%$} & \multirow{5}{*}{$\begin{array}{l}P< \\
0.001\end{array}$} \\
\hline Slight & 22 & & & \\
\hline Mild & 28 & \multirow{3}{*}{2} & \multirow{3}{*}{$64 \%$} & \\
\hline Moderate & 26 & & & \\
\hline Severe & 10 & & & \\
\hline \multicolumn{5}{|c|}{ Item 7: Feeling panic } \\
\hline None & 15 & \multirow{2}{*}{1} & \multirow{2}{*}{$36 \%$} & \multirow{5}{*}{$\begin{array}{l}P< \\
0.001\end{array}$} \\
\hline Slight & 21 & & & \\
\hline Mild & 26 & \multirow{3}{*}{2} & \multirow{3}{*}{$64 \%$} & \\
\hline Moderate & 31 & & & \\
\hline Severe & 07 & & & \\
\hline \multicolumn{5}{|c|}{ Item 8: Avoiding situations that make you panic } \\
\hline None & 32 & \multirow{2}{*}{1} & \multirow{2}{*}{$57 \%$} & \multirow{5}{*}{0.002} \\
\hline Slight & 25 & & & \\
\hline Mild & 23 & \multirow{3}{*}{2} & \multirow{3}{*}{$43 \%$} & \\
\hline Moderate & 18 & & & \\
\hline Severe & 02 & & & \\
\hline
\end{tabular}

The total score for all the items i.e somatic complaint items, depression items and total percentage for anxiety items from Level 1 cross cutting questionnaire is mentioned in Table-III. The maximum score for the two questions each of somatic complaint items and depression items is 8 and minimum score is 0 . The cut off score for 2 questions was 4 , showing minimum mild category for the two questions, while for anxiety items (3 questions), the maximum score was 12 and minimum score is 0 . The cut off score for 3 questions was 6. 


\begin{tabular}{|c|c|c|c|c|c|}
\hline \multirow[b]{2}{*}{ Score } & \multicolumn{2}{|c|}{$\begin{array}{c}\text { Somatic } \\
\text { Complaints }\end{array}$} & \multicolumn{2}{|c|}{ Depression } & \multirow{2}{*}{$\begin{array}{c}\text { Anxiety } \\
\text { Cut off } \\
\%\end{array}$} \\
\hline & $\begin{array}{c}\text { Fre- } \\
\text { quency }\end{array}$ & $\begin{array}{c}\text { Cut } \\
\text { off } \\
\text { Score } \\
\%\end{array}$ & $\begin{array}{l}\text { Fre- } \\
\text { quency }\end{array}$ & $\begin{array}{c}\text { Cut } \\
\text { off } \\
\text { Score } \\
\%\end{array}$ & \\
\hline 0 & 3 & \multirow{4}{*}{$66 \%$} & 7 & \multirow{4}{*}{$64 \%$} & \multirow{4}{*}{$50 \%$} \\
\hline 1 & 5 & & 2 & & \\
\hline 2 & 16 & & 18 & & \\
\hline 3 & 16 & & 16 & & \\
\hline 4 & 26 & \multirow{5}{*}{$34 \%$} & 21 & \multirow{5}{*}{$36 \%$} & \multirow{5}{*}{$50 \%$} \\
\hline 5 & 12 & & 7 & & \\
\hline 6 & 8 & & 19 & & \\
\hline 7 & 11 & & 7 & & \\
\hline 8 & 3 & & 3 & & \\
\hline Total & 100 & & 100 & $100 \%$ & $100 \%$ \\
\hline
\end{tabular}

Table-III. Frequency and percentages of total score of somatic questions

\section{Somatic Symptoms}

The most frequent physical complaints observed are mentioned in Table-IV and Figure-3. Headaches, lack of energy, body aches and pains, back ache and sleep deprivation are major somatic complaints noted in women.

The total score for Level 2-Somatic Symptoms Adult Patient Questionnaire is 30. The minimum and maximum score in this study is 1 and 27

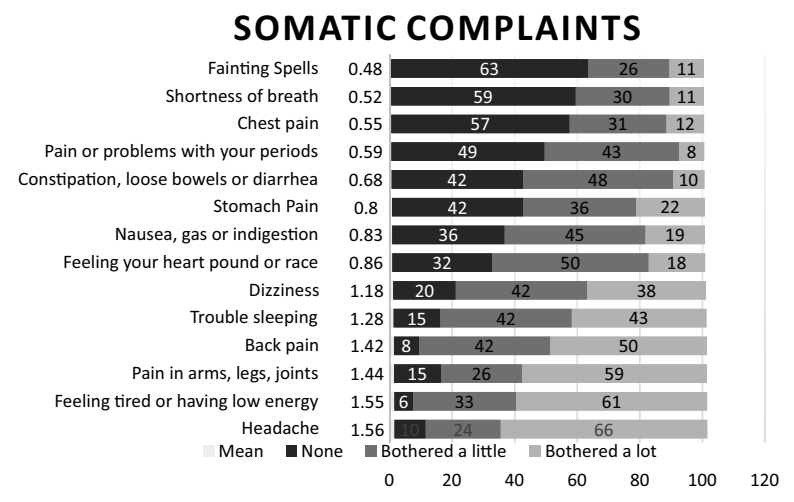

Figure-3. Somatic complaints

respectively with a mean and standard deviation of $13.74+4.825$. The prevalence of medically unexplained symptoms was found out to be 84 $\%$, which includes all high and medium score cases. 59 women had 5 or more mild to moderate somatic complaints, while 49 reported 5 or more severe complaints.

\begin{tabular}{|c|c|c|c|c|}
\hline Complaint & None & $\begin{array}{l}\text { Bothered } \\
\text { a little }\end{array}$ & $\begin{array}{c}\text { Bothered } \\
\text { a lot }\end{array}$ & Mean \\
\hline Headache & 10 & 24 & 66 & 1.56 \\
\hline $\begin{array}{l}\text { Feeling tired } \\
\text { or having low } \\
\text { energy }\end{array}$ & 6 & 33 & 61 & 1.55 \\
\hline $\begin{array}{l}\text { Pain in arms, } \\
\text { legs, joints }\end{array}$ & 15 & 26 & 59 & 1.44 \\
\hline Back pain & 8 & 42 & 50 & 1.42 \\
\hline $\begin{array}{l}\text { Trouble } \\
\text { sleeping }\end{array}$ & 15 & 42 & 43 & 1.28 \\
\hline Dizziness & 20 & 42 & 38 & 1.18 \\
\hline $\begin{array}{l}\text { Feeling your } \\
\text { heart pound } \\
\text { or race }\end{array}$ & 32 & 50 & 18 & .86 \\
\hline $\begin{array}{l}\text { Nausea, gas } \\
\text { or indigestion }\end{array}$ & 36 & 45 & 19 & .83 \\
\hline Stomach Pain & 42 & 36 & 22 & .80 \\
\hline $\begin{array}{l}\text { Constipation, } \\
\text { loose bowels } \\
\text { or diarrhea }\end{array}$ & 42 & 48 & 10 & .68 \\
\hline $\begin{array}{l}\text { Pain or } \\
\text { problems with } \\
\text { your periods }\end{array}$ & 49 & 43 & 8 & .59 \\
\hline Chest pain & 57 & 31 & 12 & .55 \\
\hline $\begin{array}{l}\text { Shortness of } \\
\text { breath }\end{array}$ & 59 & 30 & 11 & .52 \\
\hline $\begin{array}{l}\text { Fainting } \\
\text { Spells }\end{array}$ & 63 & 26 & 11 & .48 \\
\hline
\end{tabular}

Table-IV. Somatic complaints based on mean scores

Mean Comparison between various somatic categories and total scores of Level 1 - cross cutting questionnaire and Level 2 - somatic questionnaire score, and also the age of the respondents, are mentioned in Table-V. The somatic categories differed significantly for total scores of Level 1 - cross cutting questionnaire and Level 2 Somatic questionnaire score (P-Value $<0.001)$

Correlation between Level 1 questionnaire score and Level 2 somatic adult measure score indicates that both are significantly correlated (71.3 \%) with each other as depicted from 
(P-Value < 0.001). Correlation analysis between total somatic score of Items 9 and 10 and Level
2 somatic adult measure score was $54.6 \%$ with significant P-value (0.000).

\begin{tabular}{|c|c|c|c|c|c|c|c|c|}
\hline & \multicolumn{7}{|c|}{ Somatic Categories } & \multirow[b]{2}{*}{ P-Value } \\
\hline & & & Minimal & Low & Medium & High & Total & \\
\hline & $\Lambda$ & & 3 & 13 & 39 & 45 & 100 & \multirow{4}{*}{$P<0.001$} \\
\hline \multirow{3}{*}{ 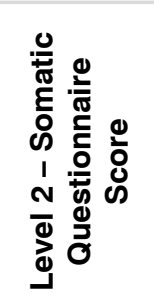 } & \multicolumn{2}{|c|}{$\begin{array}{l}\text { Mean+ Std. } \\
\text { Deviation }\end{array}$} & $2.67 \pm 1.53$ & $7.08 \pm 1.19$ & $11.97 \pm 1.51$ & $17.93 \pm 2.78$ & $13.74 \pm 4.83$ & \\
\hline & \multirow{2}{*}{ 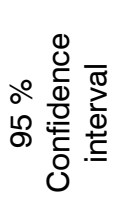 } & $\begin{array}{l}\text { Lower } \\
\text { Bound }\end{array}$ & -1.13 & 6.36 & 11.48 & 17.10 & 12.78 & \\
\hline & & $\begin{array}{l}\text { Upper } \\
\text { Bound }\end{array}$ & 6.46 & 7.79 & 12.46 & 18.77 & 14.70 & \\
\hline \multirow{3}{*}{ 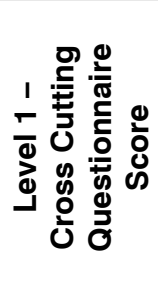 } & \multicolumn{2}{|c|}{$\begin{array}{l}\text { Mean } \pm \text { Std } \\
\text { Deviation }\end{array}$} & $3.33 \pm 1.53$ & $17.92 \pm 7.75$ & $\begin{array}{c}28.41 \pm \\
10.61\end{array}$ & $\begin{array}{c}37.38 \pm \\
10.56\end{array}$ & $\begin{array}{c}30.33 \pm \\
12.91\end{array}$ & \multirow{3}{*}{$P<0.001$} \\
\hline & \multirow{2}{*}{ 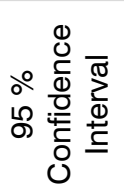 } & $\begin{array}{l}\text { Lower } \\
\text { Bound }\end{array}$ & -0.46 & 13.24 & 24.97 & 34.20 & 27.77 & \\
\hline & & $\begin{array}{l}\text { Upper } \\
\text { Bound }\end{array}$ & 7.13 & 22.61 & 31.85 & 40.55 & 32.89 & \\
\hline \multirow{3}{*}{ 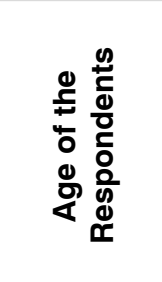 } & \multicolumn{2}{|c|}{$\begin{array}{c}\text { Mean } \pm \text { Std } \\
\text { Deviation }\end{array}$} & $\begin{array}{c}31.67 \pm \\
7.64\end{array}$ & $\begin{array}{c}34.69 \pm \\
13.86\end{array}$ & $\begin{array}{c}33.49 \pm \\
10.69\end{array}$ & $\begin{array}{c}39.91 \pm \\
11.63\end{array}$ & $\begin{array}{c}36.48 \pm \\
11.77\end{array}$ & \multirow{3}{*}{0.065} \\
\hline & \multirow{2}{*}{ 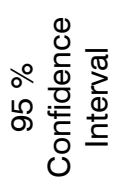 } & $\begin{array}{l}\text { Lower } \\
\text { Bound }\end{array}$ & 12.69 & 26.31 & 30.02 & 36.42 & 34.15 & \\
\hline & & $\begin{array}{l}\text { Upper } \\
\text { Bound }\end{array}$ & 50.64 & 43.07 & 36.95 & 43.40 & 38.81 & \\
\hline
\end{tabular}

\begin{tabular}{|c|c|c|c|c|c|}
\hline $\begin{array}{l}\text { S. } \\
\text { No. }\end{array}$ & X-Axis Variable (Independent Variable) & $\begin{array}{c}\text { Y-Axis Variable (Dependent } \\
\text { Variable) }\end{array}$ & r- Value & $r^{2}-$ Value & P-Value \\
\hline 1 & Level 1- Cross Cutting Questionnaire Score & Level 2 - Total Somatic Score & 0.71 & 0.508 & $<0.001$ \\
\hline 2 & Age of Respondents & Level 2 - Total Somatic Score & 0.20 & 0.041 & 0.044 \\
\hline 3 & Somatic Questions (Items 9 and 10) Score & Level 2 - Total Somatic Score & 0.546 & 0.299 & $<0.001$ \\
\hline
\end{tabular}

The scatter plot for Level 1 cross cutting questionnaire and Level 2 somatic adult measure is as follows;

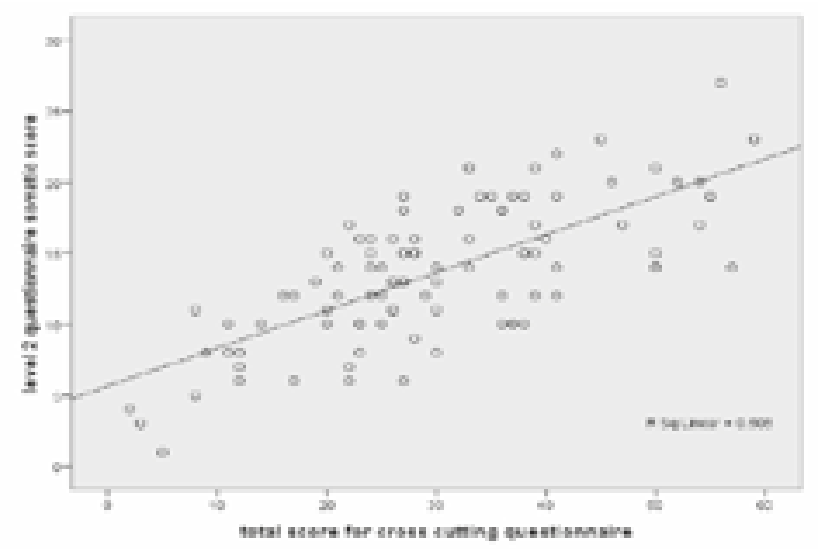

\section{DISCUSSION}

The study aimed to determine prevalence of somatization in female population presenting at Nahaqi Emergency Satellite Hospital (NESH). Based on present study findings majority of female patients attending different OPD's were suffering from somatoform disorders presenting as medically unexplained symptoms.

Population studies done internationally link somatization to cultural contexts. Asians more frequently have physical symptoms than the western communities. ${ }^{6}$ This study found similar patterns of psychological illnesses manifesting as somatic complaints in effected women. The 
prevalence of anxiety and depression in our study was found out to be 50 and $57 \%$ respectively while majority of complaints were somatic in nature. From a rural background, a study from Pakistan showed the prevalence of anxiety and depression to be $66 \%$ with women manifesting their depression as physical somatic complaints. ${ }^{5}$ $84 \%$ women reported at least one medically unexplained symptoms with $59 \%$ having 5 or more milder complaints and $49 \%$ having 5 or more severe complaints. This high prevalence of medically unexplained symptoms is also reported by other studies done elsewhere,$^{13}$ though a wide variation exists when strict diagnostic criteria are applied for other conditions. Another study from Germany reported $81.6 \%$ prevalence of at least one symptom of MUS, with $22.1 \%$ population having one severe impairment. ${ }^{1}$ Somatization was associated with female gender, the evidence of which exists in various systematic reviews done on the subject ${ }^{7,9,10}$ which is the reason we chose exclusively the female population. Low socio-economic status and low education levels was also associated with somatization which is consistent with our study. ${ }^{1,5}$

Most common complaints from this study are pains (headache, backache, arthralgia and pain during menstruation) and lack of energy/ asthenia; (the details are mentioned in table 4) which is similar to study done by Hiler and Reif. ${ }^{1}$ The symptoms rarely occur single and most of the women reported cluster of symptoms ranging from mild to severe degrees. In this study, it was noticed that nearly half of the population was experiencing severe impairment, which was clinically significant. Majority of the somatization complaints have pain predominance as compared to complaints of gastro-intestinal tract. This study also found similar preponderance of syndromic pain in women attending OPD's in rural set up. Findings are consistent with findings from related studies. ${ }^{1,5,12}$

\section{Study Limitations}

Although with good response rate, community participation and local data collection this study provided an insight about the prevalence of medically unexplained symptoms and somatization.

Owing to time limitations, we studied small sample size which may not be a true representative of the rural population. Strict diagnostic criteria for various sub categories of somatoform disorders was not applied and so, we included mild cases in our analysis.

The prevalence of medically unexplained symptoms and somatization is quite high in women in Nahaqi, KPK- Pakistan more studies with increased sample size and diagnostic criteria can be done to evaluate the effects of these condition on daily lives of the individuals.

\section{CONCLUSION}

This study reveals that somatization and medically unexplained symptoms are frequently happening phenomenon, which the physicians and GP's encounter on daily basis. Although these visits are an extra stress on health service resources and on the attending physician as well. The nonsatisfaction of the patient needs bio-psychosocial model and community involvement to treat such cases. Our study endorsed the prevalence of these symptoms in primary care settings as indicated by international and national studies.

Copyright@ 25 May, 2019.

\section{REFERENCES}

1. Hiller W, Rief W, Brähler E. Somatization in the population: From mild bodily misperceptions to disabling symptoms. Soc Psychiatry Psychiatr Epidemiol. 2006; 41(9):704-12.

2. Garralda ME. Unexplained physica I complaints. Child Adolesc Psychiatry Clin NA [Internet]. 2010; 19(2):199209. Available from: http://dx.doi.org/10.1016/j. chc.2010.01.002

3. Grover S, Aneja J, Sharma A, Malhotra R, Varma S, Basu $D$, et al. Do the various categories of somatoform disorders differ from each other in symptom profile and psychological correlates. Int J Soc Psychiatry. 2015; 61(2):148-56.

4. Creed F, Guthrie E, Fink P, Henningsen P, Rief W, Sharpe $\mathrm{M}$, et al. Is there a better term than "Medically unexplained symptoms"? J Psychosom Res. 2010; 68(1):5-8. 
5. Minhas FA, Nizami AT. Somatoform disorders: Perspectives from Pakistan. Int Rev Psychiatry. 2006; 18(1):55-60.

6. Grover S, Ghosh A. Somatic symptom and related disorders in Asians and Asian Americans. Asian J Psychiatr [Internet]. Elsevier B.V.; 2014; 7(1):779. Available from: http://dx.doi.org/10.1016/j. ajp.2013.11.014

7. Hilderink PH, Collard R, Rosmalen JGM, Oude Voshaar RC. Prevalence of somatoform disorders and medically unexplained symptoms in old age populations in comparison with younger age groups: A systematic review. Ageing Res Rev [Internet]. Elsevier B.V.; 2013; 12(1):151-6. Available from: http:// dx.doi.org/10.1016/j.arr.2012.04.004

8. Al-sayyad HHW, Saddick EA, Al-omer DK. Prevalence rate of somatization and psychological disorder among patients consulting out patient clinic in Nasiriyah. 2010; 2010(2).

9. Desai G, Chaturvedi SK. Gender and somatoform disorders: Do subtypes of somatoform disorders differ? Asian J Psychiatr [Internet]. Elsevier B.V.; 2013; 6(6):609-10. Available from: http://dx.doi.org/10.1016/j. ajp.2013.06.015

10. Vargas-Prada S, Coggon D, Ntani G, Walker-Bone K, Palmer KT, Felli VE, et al. Descriptive epidemiology of somatising tendency: Findings from the CUPID study. PLoS One [Internet]. 2016; 11(4):1-17. Available from: http://dx.doi.org/10.1371/journal.pone.0153748

11. Löwe B, Spitzer RL, Williams JBW, Mussell M, Schellberg D, Kroenke K. Depression, anxiety and somatization in primary care: Syndrome overlap and functional impairment. Gen Hosp Psychiatry. 2008; 30(3):191-9.
12. Mohan I, Lawson-Smith C, Coall DA, Van Der Watt $\mathrm{G}$, Janca A. Somatoform disorders in patients with chronic pain. Australas Psychiatry. 2014; 22(1):66-70.

13. Haller H, Cramer H, Lauche R, Dobos G. Somatoform disorders and medically unexplained symptoms in primary care: A systematic review and meta-analysis of prevalence. Dtsch Arztebl Int. 2015; 112(16):279-87.

14. Sumathipala A, Siribaddana S, Hewege $S$, Sumathipala $K$, Prince $M$, Mann A. Understanding the explanatory model of the patient on their medically unexplained symptoms and its implication on treatment development research: A Sri Lanka Study. BMC Psychiatry. 2008; 8:1-10.

15. Olde Hartman TC, Borghuis MS, Lucassen PLBJ, van de Laar FA, Speckens AE, van Weel C. Medically unexplained symptoms, somatisation disorder and hypochondriasis: Course and prognosis. A systematic review. J Psychosom Res [Internet]. Elsevier Inc.; 2009; 66(5):363-77. Available from: http://dx.doi. org/10.1016/j.jpsychores.2008.09.018

16. Afridi MI, Siddiqui MA, Ansari A. Gastrointestinal somatization in males and females with depressive disorder. J Pak Med Assoc. 2009; 59(10):675-9.

17. American Psychiatric Association. DSM-5 self-rated level 1 cross-cutting symptom measure-adult. Am Psychiatr Assoc [Internet]. 2013; Available from: http://www.psychiatry.org/practice/dsm/dsm5/onlineassessment-measures

18. American Psychiatric Association. APA_DSM5_level-2somatic-symptom-adult. pdf. 2013.

\begin{tabular}{|c|c|c|c|}
\hline \multicolumn{3}{|c|}{ AUTHORSHIP AND CONTRIBUTION DECLARATION } \\
\hline Sr. \# & Author-s Full Name & \multicolumn{1}{|c|}{ Contribution to the paper } & Author=s Signature \\
\hline 1 & Ali Raza & $\begin{array}{l}\text { Conceive, designed, reviewed } \\
\text { and editing of manusctipt. } \\
\text { Data collection, Entry. } \\
\text { Management and literature } \\
\text { review. }\end{array}$ \\
\hline 2 & Hajira Zainab & \\
\hline
\end{tabular}

